\title{
BMJ Open Pilot study for the registry of complications in rheumatic diseases from the German Society of Surgery (DGORh): evaluation of methods and data from the first 1000 patients
}

\author{
Tanja Kostuj, ${ }^{1,2}$ Stefan Rehart, ${ }^{3}$ Ronald Matta-Hurtado, ${ }^{4}$ Christoph Biehl, ${ }^{4,5}$ \\ Roland E Willburger, ${ }^{6}$ Klaus Schmidt, ${ }^{4}$ On behalf of the study group "complication- \\ register of the DGORh"
}

To cite: Kostuj T, Rehart S, Matta-Hurtado R, et al. Pilot study for the registry of complications in rheumatic diseases from the German Society of Surgery (DGORh): evaluation of methods and data from the first 1000 patients. BMJ Open 2017;7:e015987. doi:10.1136/ bmjopen-2017-015987

- Prepublication history for this paper is available online. To view these files please visit the journal online (http://dx.doi. org/10.1136/bmjopen-2017015987).

Received 16 January 2017 Revised 19 June 2017 Accepted 21 June 2017

CrossMark

For numbered affiliations see end of article.

Correspondence to

Dr. Tanja Kostuj;

tanja.kostuj@t-online.de

\section{ABSTRACT}

Objective Most patients suffering with rheumatic diseases who undergo surgical treatment are receiving immune-modulating therapy. To determine whether these medications affect their outcomes a national registry was established in Germany by the German Society of Surgery (DGORh). Data from the first 1000 patients were used in a pilot study to identify relevant corisk factors and to determine whether such a registry is suitable for developing accurate and relevant recommendations. Design and participants Data were collected from patients undergoing surgical treatments with their written consent. A second consent form was used, if complications occurred. During this pilot study, in order to obtain a quicker overview, risk factors were considered only in patients with complications. Only descriptive statistical analysis was employed in this pilot study due to limited number of observed complications and inhomogeneous data regarding the surgery and the medications the patients received. Analytical statistics will be performed to confirm the results in a future outcome study.

Results Complications occurred in 26 patients and were distributed equally among the different types of surgeries. Twenty one of these patients were receiving immunemodulating therapy at the time, while five were not. Infections were observed in $2.3 \%$ of patients receiving and in $5.1 \%$ not receiving immunosuppression.

Conclusions Due to the low number of cases, inhomogeneity in the diseases and the treatments received by the patients in this pilot study, it is not possible to develop standardised best-practice recommendations to optimise their care. Based on this observation we conclude that in order to be suitable to develop accurate and relevant recommendations a national registry must include the most important and relevant variables that impact the care and outcomes of these patients.

\section{INTRODUCTION}

Rheumatoid arthritis (RA) has a prevalence of approximately $1 \%$ in Western Europe and the USA, with a cumulative prevalence for all

\section{Strengths and limitations of the study}

- Data from 1000 patients, from 12 health care centres with varying organizational structures, were available to test.

- Due to the small number of patients with complications, the inhomogeneity in the different types of rheumatic diseases and the treatments received by patients, extended statistical analyses was not possible and only tendencies could be derived.

types of rheumatic diseases being $2 \%$, and the incidence of inflammatory arthritis diseases in Germany is $3 \%$ (about 2.5 billion patients). About 25 years ago, approximately $25 \%$ of these patients underwent total joint replacement, yet recently, the number of these procedures as well as the number of surgical treatments in general in patients with RA has decreased in Europe, the USA and Japan. ${ }^{1-8}$ This trend could be the result of the recently introduced, very early 'treat-to-target' treatment and/or the use of modern anti-inflammatory medications, ${ }^{9}$ which have increased during the same time period. Actually, about $70 \%$ of the patients with RA have received so-called disease-modifying antirheumatic drugs (DMARDs), while about $20 \%$ are treated with biologicals such as immune-modulating therapy. ${ }^{10}$ This means that most of these patients, undergoing surgical treatments, are receiving immune-modulating therapy for their inflammatory arthritic diseases. However, it remains unclear whether immune-modulating medications affect the outcomes of these surgical treatments or if they contribute to an increase in the number of wound complications. 
Interestingly, for most of the 20 routinely administered DMARDs or biologicals, there are surprisingly few evidence-based recommendations for their perioperative use when complications occur. ${ }^{2}{ }^{9}$ For example, in the case of methotrexate, the recommendation to continue administration was based on the expert opinion of a broad international panel of rheumatologists. ${ }^{11}$ National medical societies in France, the Netherlands, the US, UK and Japan recommend that-concerning tumour-necrosis-factor alpha (TMF- $\alpha$ ) — therapy should be substituted until wounds are healed. ${ }^{12-15}$ Based on this confusion, the German Society for Orthopaedics in Rheumatic Diseases (DGORh) established a national registry that included surgical patients suffering with inflammatory arthritis disease. The aim of this pilot study was to determine if data from this national registry could be used to identify risk factors to develop accurate and relevant treatment recommendations, for example, in patients with RA receiving medications who have subcutaneous or deep wound infections.

This report presents the methods used in this pilot study and the preliminary results, from the first 1000 patients.

\section{MATERIALS AND METHODS \\ Risk adjustment}

Based on rheumatology textbooks, published studies ${ }^{215-19}$ and the clinical experience of study group members, the following risk factors were identified as being possible confounders as it relates to wound disorders or non-unions in arthrodesis: diabetes mellitus, atherosclerosis, malignant tumours, cachexia due to HIV or other consuming diseases, corticoid therapy with more than $5 \mathrm{mg}$ prednisolone equivalent and/or administration for more than 1 year, current or history of bacterial infection in the wound or alio loco. In addition, other risk factors that were included were: sex, age, body mass index (BMI), American Society of Anesthesiologists (ASA) Physical Status classification, alcohol and smoking history.

In order to obtain a quicker overview of these possible risk factors/possible confounders, these were only considered in those patients who had wound disorders during the pilot study. While this might have caused a bias in statistical analyses and interpretation of data concerning wound disorders, seroma and infection, we accept this, since the main focus of this pilot study was to see if risk factors are present and since we did not expect to have enough data to perform statistical analyses. In the actual registry data, this bias would not occur since all risk factors and confounders must be reported in the basic form, in order to obtain valid statistical data.

\section{Number and structure of centres involved in the pilot study}

A total number of 12 centres were included in the pilot study (box).

Each centre had an orthopaedic surgeon with experience treating patients with inflammatory arthritic diseases. In order to have a representative cross-section
Box Departments participating in the pilot study

Orthopedic Hospital Harthausen, Bad Aibling

- Department of Rheuma-Surgery, Kreuznacher Diakonie, Bad Kreuznach

- Department of Rheuma-Surgery, Red Cross Hospital, Bremen

- Department of Rheuma-Orthopaedics, St. Elisabeth Hospital, University Hospital (Ruhr University Bochum), Bochum

- Orthopaedics, Traumatology and Rheuma-Orthopaedics Clinic, Katholic Hospital Dortmund-West, Dortmund

- Orthopaedics and Traumatology Clinic, Agaplesion Markus Hospital, Frankfurt/Main

- Orthopaedics, Traumatology and Rheuma-Orthopaedics Clinic, Westpfalzclinic Kusel, Kusel

- Orthopaedic and Policlinic, University Hospital Leipzig, Leipzig

- Rheuma-ortphopedics, Rheinisches Centre for Rheumatology Meerbusch, Meerbusch

- Orthopaedic Department, Collm-Clinic Oschatz, Oschatz

- Rheuma-Orthopaedics, North-Western Centre for Rheumatology St Josef-Stift Sendenhorst, Sendenhorst

of the different types of providers in Germany, different types of departments that treat patients with rheumatic diseases were asked to participate: hospitals specialised in rheumatology, university-based hospitals, departments whose focus was elective orthopaedic surgery and departments that focus on treating patients with trauma.

\section{Ethical approval}

Approval to conduct the study was obtained from the ethics committee at Ruhr University in Bochum (no: 4138-11). The study was carried out in accordance with the Declaration of Helsinki. All patients included in the study were invited and gave their written informed consent in an initial consent form. This form, administered by the attending physician, included information about different types of rheumatic diseases, their onset, types of medications administered to patients with rheumatic disease, details about medication regimens (continued or interrupted, estimated time for restarting medication, etc) and surgical treatments (date and type of surgery).

If a complication occurred, a second consent form was used that included information about risk factors, date and type of observed complication, as well as indicated treatments. This pilot study focused on the following complications and treatments: wound disorders and skin necrosis (delayed removal of stitches, type of local treatment, local suture), seroma (evacuation, local suture, reoperation), subcutaneous infections (CDC A1) (with i.v. antibiotics treatment or reoperation), deep infections (CDC A2+A3) (i.v. antibiotics and reoperation). Minor complications that did not result in an appointment at the outpatient department or readmission but instead were treated in a doctor's office were not taken into account.

\section{Patients}

Every patient suffering from inflammatory arthritis disease and receiving surgical treatment in one of the 


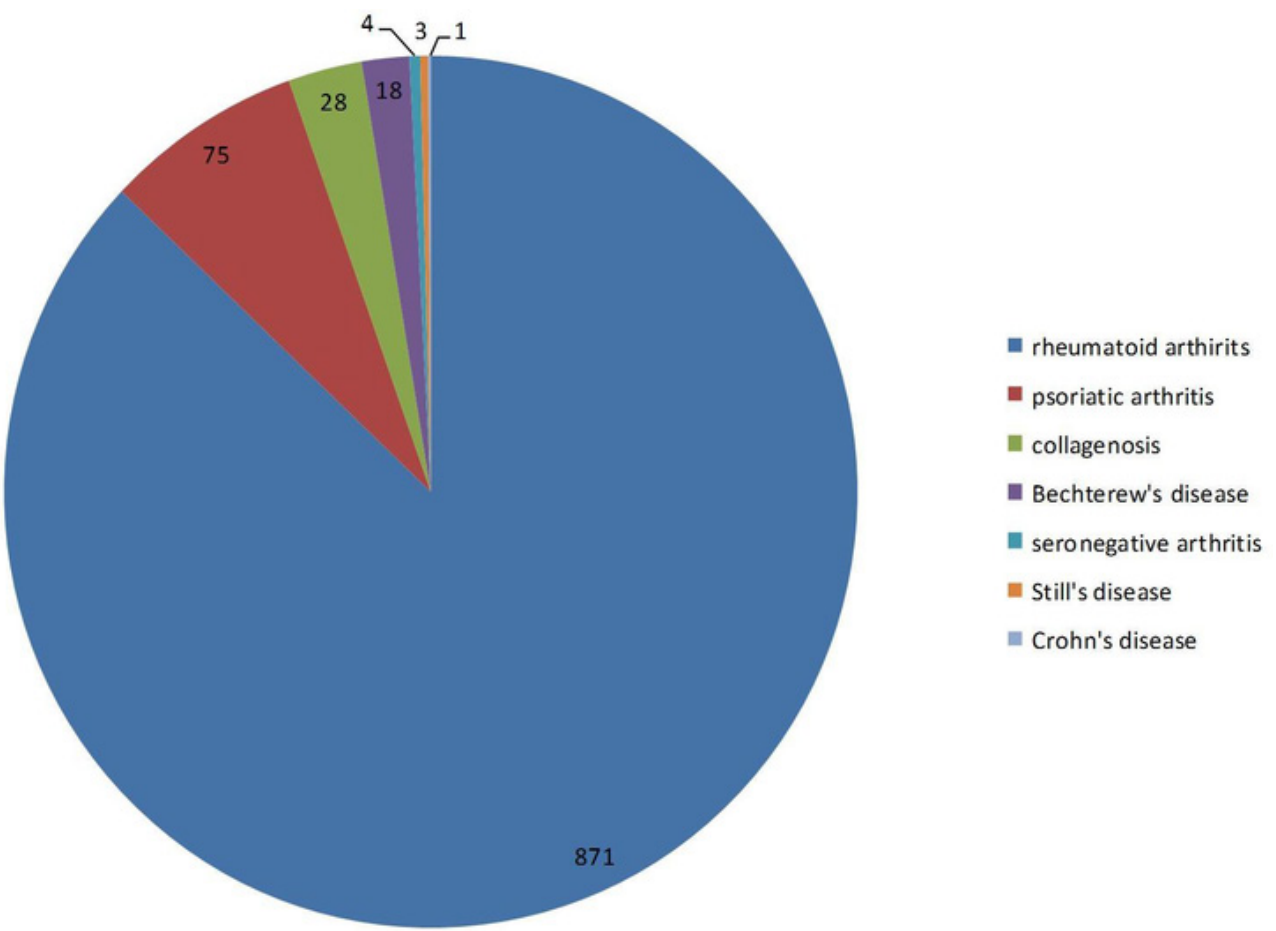

Figure 1 Distribution of different rheumatic diseases among the 1000 pilot study patients.

centres was asked to participate in this study and was included after written informed consent was given. Inflammatory arthritis and elective surgical treatment in the musculoskeletal system was the only inclusion criteria. No exclusion criteria were defined. No dropouts/withdrawal of consent occurred during this pilot study. The majority of the patients included in this pilot study (871 cases, $87 \%$ ) suffered from RA, while $7.5 \%$ had a psoriatic arthritis, $2.8 \%$ suffered from a collagenosis and $1.8 \%$ suffered from ankylosing spondylosis. Other rare diagnoses included not differentiated inflammatory arthritis (four cases, $0.4 \%$ ), Still's disease (three cases, $0.3 \%$ ) and Crohn's disease (one case, $0.1 \%$ ) (figure 1 ).

The median period of time from onset of the disease to the procedure leading to their inclusion in the study was 16 years, with an IQR of $10-25$ years, with a maximum of 64 years and a minimum of 1 year.

\section{Statistical methods}

This article focuses on the methods and the adaptation of the questionnaires for use in the registry and reports on the initial results from the first 1000 subjects included in the database.

Due to the limited number of observed complications and the inhomogeneous type of the surgical treatments and the medications used, only descriptive statistical analysis was appropriate in this pilot study. However, analytical statistics of the confirmatory questions in midterm outcome can be expected from the registry, which was established in the summer of 2014.

Medians, interquartile ranges, CIs and significance (at $5 \%$ level) for the incidence of wound complications in patients treated with immune-modulating medication compared with those not treated were computed using SPSS V.22.0 for Windows (IBM).

\section{RESULTS}

\section{Anti-inflammatory drugs}

More than $90 \%$ of patients (902) received pharmacological therapy, with $6 \%$ (60 patients) treated with corticosteroids as a monotherapy and 20\% (197 patients) receiving a combination of DMARDs or biologicals and steroids. The majority $(84 \%, 840$ patients) were treated with immune-modulating therapy based on DMARDS or biologicals, with $45 \%$ (453 patients) receiving methotrexate, either as a monotherapy $(19 \%, 191$ patients) or in combination with corticosteroids $(11 \%, 109$ patients) or adalimumab (11\%, 106 patients). Other common drugs were leflunomide in $(18 \%, 179$ patients) of which $7 \%$ (67 patients) received a monotherapy, and etanercept $(12 \%, 121$ patients) of which 5\% (47 patients) received a monotherapy.

Overall, more than half of all patients received a monotherapy $(51 \%, 507$ patients), while $32 \%$ were treated with two different types of medication. Combinations of three (68 patients) or four different types of immune-modulating medications (2 patients) were rare and were reported in $7 \%$ and $0.2 \%$ of patients, respectively. The reported combinations are shown in table 1 .

\section{Types of surgery}

Nearly one third of all procedures can be categorised as bone and joint procedures: total joint replacements, 
Table 1 Pharmacological therapy: steroids, disease-modifying antirheumatic drugs, biologicals and their combinations as reported

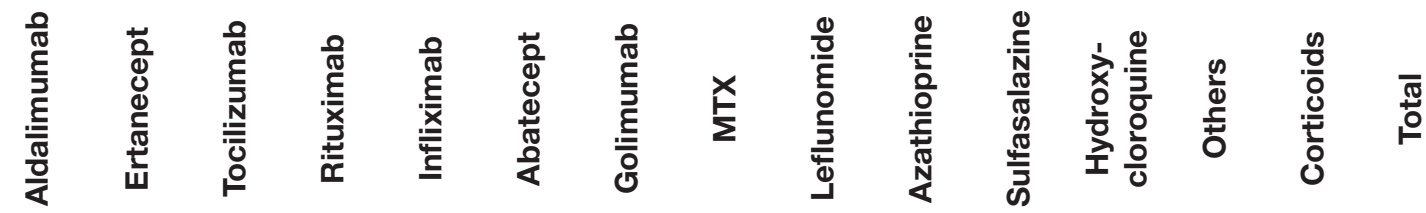

\begin{tabular}{lrrrrrrrrrrrrrrr}
\hline Aldalimumab & 28 & 0 & 0 & 0 & 0 & 0 & 0 & 106 & 6 & 1 & 2 & 1 & 4 & 0 & 68 \\
Ertanecept & 0 & 47 & 0 & 0 & 0 & 0 & 0 & 41 & 17 & 1 & 4 & 3 & 1 & 24 & 121 \\
\hline Tocilizumab & 0 & 0 & 12 & 0 & 0 & 0 & 0 & 4 & 1 & 0 & 2 & 0 & 0 & 3 & 20 \\
\hline Rituximab & 0 & 0 & 0 & 16 & 0 & 0 & 0 & 11 & 2 & 0 & 2 & 2 & 0 & 6 & 35 \\
\hline Infliximab & 0 & 0 & 0 & 0 & 3 & 0 & 0 & 5 & 0 & 0 & 1 & 0 & 0 & 2 & 9 \\
\hline Abatecept & 0 & 0 & 0 & 0 & 0 & 3 & 0 & 6 & 2 & 0 & 0 & 1 & 0 & 2 & 9 \\
Golimumab & 0 & 0 & 0 & 0 & 0 & 0 & 3 & 7 & 0 & 0 & 0 & 0 & 0 & 6 & 15 \\
MTX & 106 & 41 & 4 & 11 & 5 & 6 & 7 & 191 & 43 & 2 & 31 & 24 & 10 & 109 & 453 \\
Leflunomide & 6 & 17 & 1 & 2 & 0 & 2 & 0 & 43 & 67 & 1 & 15 & 5 & 5 & 40 & 179 \\
Azathioprine & 1 & 1 & 0 & 0 & 0 & 0 & 0 & 2 & 1 & 10 & 0 & 1 & 0 & 5 & 18 \\
Sulfasalazine & 2 & 4 & 2 & 2 & 1 & 0 & 0 & 31 & 15 & 0 & 34 & 8 & 0 & 19 & 99 \\
Hydroxycloroquine & 1 & 3 & 0 & 2 & 0 & 1 & 0 & 24 & 5 & 1 & 8 & 11 & 1 & 22 & 57 \\
Others & 4 & 1 & 0 & 0 & 0 & 0 & 0 & 10 & 5 & 0 & 0 & 1 & 10 & 1 & 32 \\
Corticoids & 6 & 24 & 3 & 6 & 2 & 2 & 6 & 109 & 40 & 5 & 19 & 22 & 1 & 60 & 253 \\
\hline
\end{tabular}

MTX, methotrexate.

Table 2 Type of surgery performed and affected areas in the 1000 patients

\begin{tabular}{|c|c|c|c|c|c|c|}
\hline & Tenosynovectomy & Synovectomy & $\begin{array}{l}\text { Fusion or resection } \\
\text { arthroplasty }\end{array}$ & $\begin{array}{l}\text { Total joint } \\
\text { replacement }\end{array}$ & Others & Total \\
\hline Vertebra column & & & 3 & 1 & 2 & 6 \\
\hline Shoulder & 7 & 8 & 6 & 17 & & 38 \\
\hline Elbow & 1 & 14 & 7 & 6 & 5 & 33 \\
\hline Wrist & & 26 & 55 & 2 & 11 & 94 \\
\hline Flexor tendons (hand) & 12 & & & & & 12 \\
\hline Extensor tendons (hand) & 19 & & & & & 19 \\
\hline MCP joints & & 5 & 9 & 17 & 1 & 32 \\
\hline DIP/PIP joints (hand) & & 4 & 19 & 4 & 7 & 34 \\
\hline Hip & & & 3 & 148 & & 151 \\
\hline Knee & 1 & 56 & 4 & 175 & 4 & 240 \\
\hline Ankle joint & 4 & 4 & 21 & 9 & 5 & 43 \\
\hline Subtalar joint & 2 & 1 & 27 & & 2 & 32 \\
\hline Toes & 3 & 9 & 167 & 1 & 14 & 194 \\
\hline Tendons foot & 6 & & 3 & & 5 & 14 \\
\hline Others & & & & & 58 & 58 \\
\hline Total: & 55 & 127 & 324 & 380 & 114 & 1000 \\
\hline
\end{tabular}

DIP/PIP joints, distal interphalangeal/proximal interphalangeal joints; MCP joints, metacarpophalangeal joints.

arthrodeses and resection arthroplasty. Different types of synovectomies were performed in $18 \%$ of patients. Surgeries in the lower extremity were represented far more often $(67 \%, 674$ cases) than those in the upper extremities (26\%, 262 cases). Only two patients with surgical treatment of the vertebral column were included $(0.2 \%)$. The different types of surgical treatments are listed in table 2. 


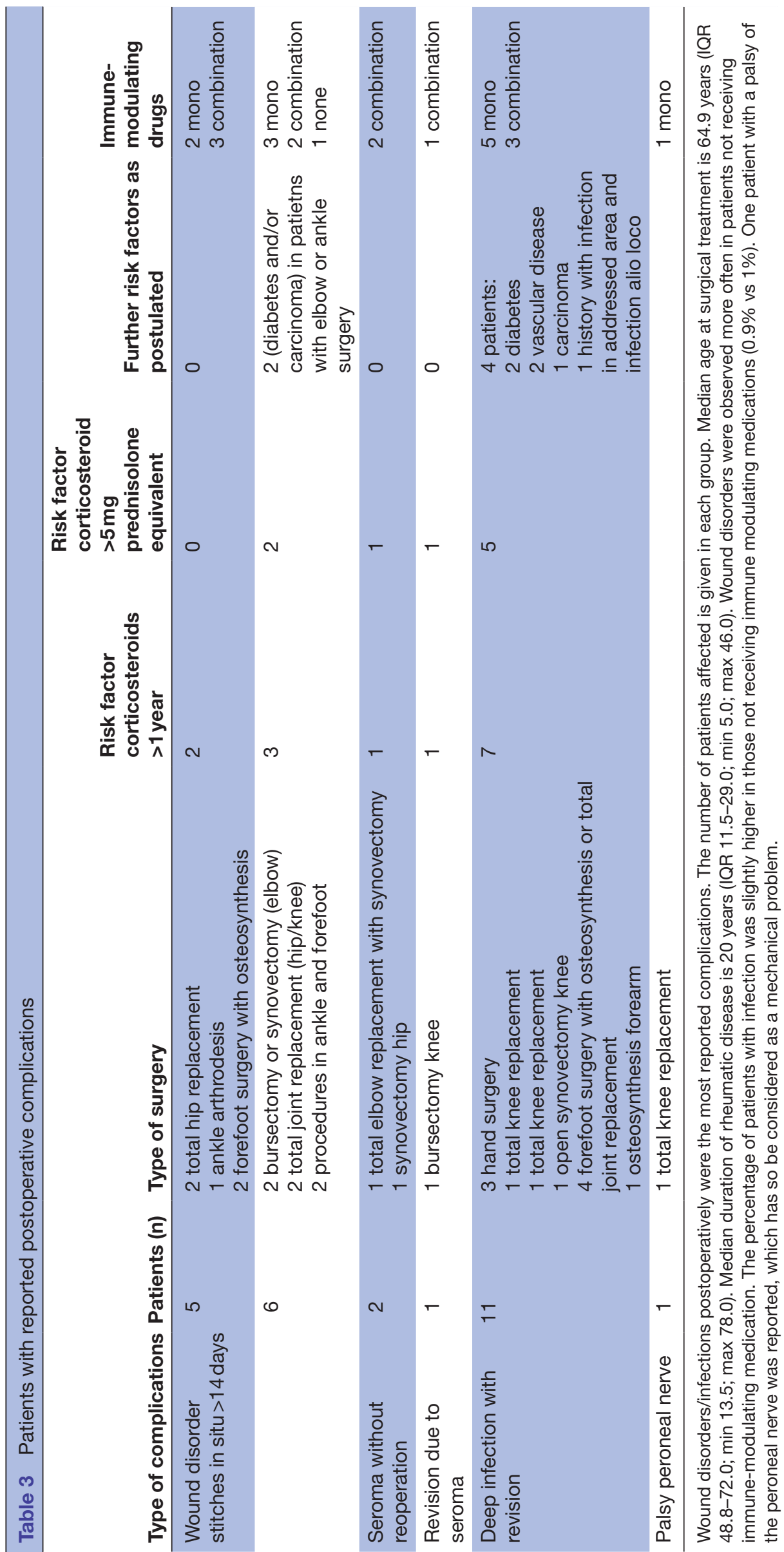




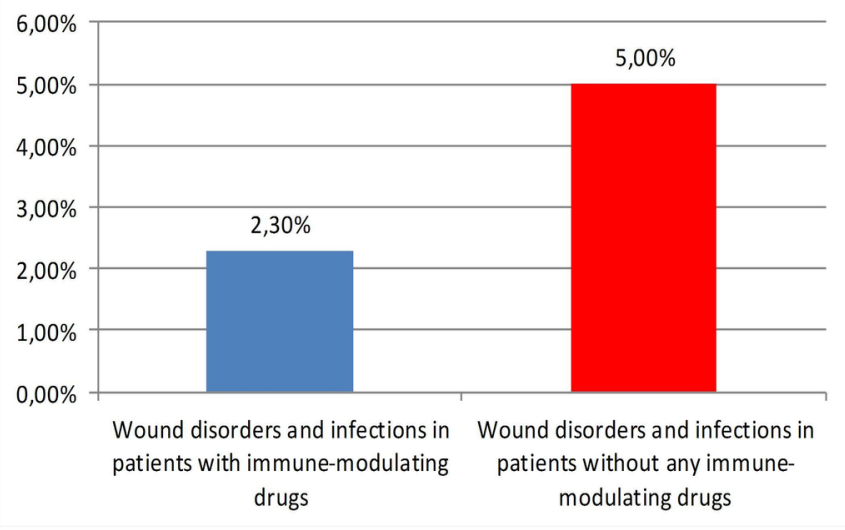

\begin{tabular}{|l|l|l|l|}
\hline & No wound complications & Wound complications & \\
\hline No immune-modulating drugs & $\mathrm{n}=93(94.9 \%)$ & $\mathrm{n}=5(5.1 \%)$ & $\mathrm{n}=98$ \\
\hline Immune-modulating drugs & $\mathrm{n}=881(97.7 \%)$ & $\mathrm{n}=21(2.3 \%)$ & $\mathrm{n}=902$ \\
\hline & $\mathrm{n}=974$ & $\mathrm{n}=26$ & $\mathrm{n}=1000$ \\
\hline
\end{tabular}

Figure 2 Wound disorders and infections occurred more than twice as often in patients not receiving immunemodulating medication, compared with treated patients. There was no statistical significance (Fisher's exact test, $p=0.168,5 \%$ level) in the occurrence of wound complications between patients treated with immune-modulating drugs and those not treated.

\section{Complications occurred}

Complications, summarised as 'wound disorders,' and infections occurred in 26 patients (2.6\%) and were nearly equally distributed among upper limb, total hip or knee replacement and foot and ankle surgeries. Twenty one of these patients received pharmacological immune-modulating therapy (interrupted perioperatively in 11 cases), while five did not receive a specific medication. A total of $2.3 \%$ of patients with an immunomodulating therapy had wound complications, while $5.1 \%$ receiving no pharmacotherapy for their rheumatoid disease experienced wound complications in the form of infections.

Deep infections requiring revision surgery occurred in nine patients, eight $(0.8 \%)$ of which were being treated with immune-modulating drugs and one $(0.1 \%)$ who was not receiving medication.

Of the 26 patients with wound complications, 14 (54\%) had been treated with corticosteroids for more than 1 year and 9 patients (35\%) were receiving doses greater than a $5 \mathrm{mg}$ prednisolone equivalent. Four patients $(15 \%)$ had diabetes mellitus, two patients $(8 \%)$ had vascular disease in the treated limb, two patients $(8 \%)$ had carcinoma (none with cachexia) and one patient (4\%) had a history of infection at the time of surgery. The average age of the patients with wound disorders/infections at the time of surgery was 65 (IQR 49-72, minimum 14, maximum 78) years. The duration of the inflammatory arthritic disease was 18 (IQR 10-29, minimum 5, maximum 46) years (95\% CI 11 to 27 years). Details for these 26 patients with wound complications/infections are given in table 3 .

\section{DISCUSSION}

Our initial results in this pilot study show that wound complications occurred twice as often in patients not receiving immune-modulating medication, while deep infections were nearly equally distributed in patients receiving and not receiving drug therapy. This finding seems to be clinically relevant-even if the statistical significance was not demonstrated, using the Fisher's exact test $(\mathrm{p}=0.168)$ (figure 2). However, due to the surprisingly low number of complications, the inhomogeneous surgical procedures and the variance of pharmacotherapy within the pilot data, this observation must be interpreted with care and analytical statistics cannot yet be performed.

That said, these initial observations support the need to collect additional data that include risk factors, types of surgeries and pharmacotherapy in order to be able to formulate evidence-based recommendations for these patients.

This pilot study has helped to identify possible confounders such as risk factors and loss to follow-up due to missing patient identification, both important factors that must be taken into consideration as data collection moves forward.

The postulated risk factors were found in patients with wound disorders, indicating that these risk factors will have to be considered as possible confounders in order to evaluate the influence of pharmacotherapy on wound complications. Based on this observation, these risk factors have been included in the initial patient inclusion criteria forms ('basic questionnaire'). This will make it possible to perform risk-adjusted analyses combined with age, sex, BMI, ASA classification, alcohol and smoking history, type and onset of rheumatic disease, in the actual registry (figure 3 ). Taking these confounders into account will help formulate more accurate and relevant preoperative recommendations related to the influence of pharmacotherapy in these patients.

The surprisingly low number of patients with postoperative wound disorders and infection compared with the considerably higher figure published in literature $e^{102021}$ can be explained by the loss to follow-up of patients with minor wound complications treated with local therapy outside the hospital. These patients were not included in this study because the ID assigned to them by their respective hospitals made follow-up impossible as they received care elsewhere. To remedy this, a patient pseudonym was generated based on non-changing patient data consisting of date and location they were attended, place of birth (city and state), Christian name and maiden name. This so called 'salt-protected hash code' ensures that, even in the most complicated forms and between different institutions, patients can be linked to their individual data set, helping to avoid a loss to follow-up in the actual registry. 
DGORh - Sammelstatistik Bogen 1

BASISTHERAPIE

Erfassung der Basistherapie bei Rheumaoperationen

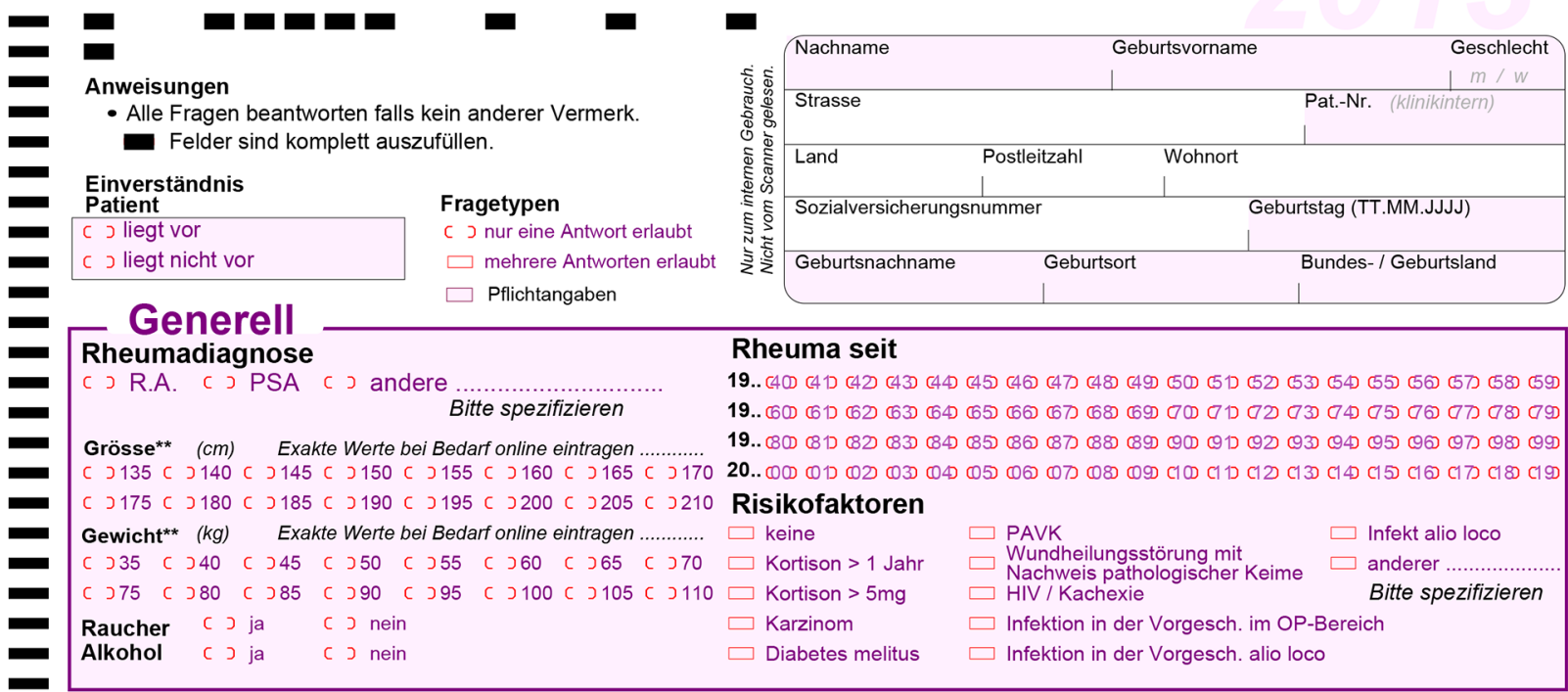

\section{- Operation Bei Komplikationen Bogen 2 ausfüllen}

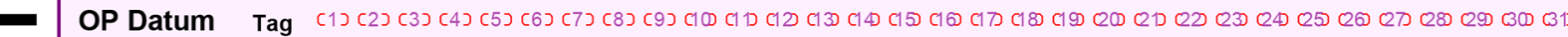

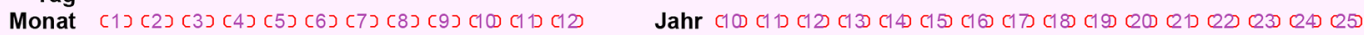
CRP prä-OP

Prä-OP quantitativer Rheumafaktor

(optional)

Allgemeinzustand (ASA)

c J nicht bekannt $\quad$ c $>$ ASA2, geringe
c J ASA1, gesund
Beeinträchtigung

c J ASA3 starke Beeintr,

c J ASA4 lebensbedr. Beeintr. C J ASA5 moribund \begin{tabular}{|l|l|l|l|l|c|c|}
\hline OP Art & Tenosynovekt. & Synovektomie & Sehnenplastiken & Arthrodese & Arthroplastik & Endoprothese \\
\hline
\end{tabular}

m

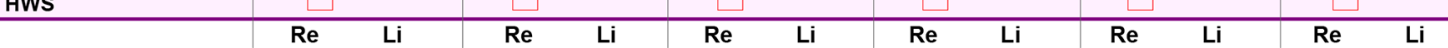

Schulter

Ellbogen

Handgelenk

Strecksehnen Hand

Beugesehnen Hand

MCP I

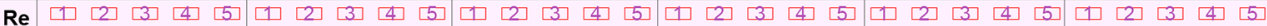

2 MTP

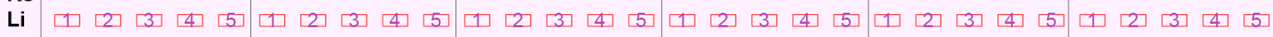

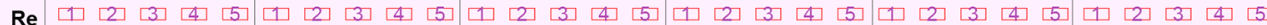

PIP I

$\square$ DIP

PIP I

DIP

BWS ILWS

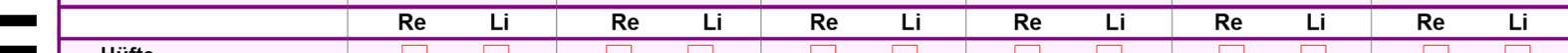

Hüfte

Knie

OSG

USG

Beugesehnen Fuss

Strecksehnen Fuss

Fusswurzel

Rück- und Mittelfuss

Zehengelenke

Andere $\quad$ c J andere OP

Bitte spezifizieren

Allgemeine Bemerkungen:

Figure 3 Continued 
DGORh - Sammelstatistik Bogen 1

Erfassung der Basistherapie bei Rheumaoperationen

BASISTHERAPIE

Seite 2

\section{=}

\section{$=$\begin{tabular}{c|c|c}
$\mathbb{B}$ \\
Handels- & HWz & eingenommen prä-op Monate \\
name zage & Tage
\end{tabular}}

\begin{tabular}{l|l|l|l} 
Instruktion & name z.B. & & \multicolumn{1}{c}{$\begin{array}{l}\text { max. } 3 \text { Markierungen anbringen } \\
\text { - oberste Zeile sind Hunderter } \\
\text { - zweite Zeile sind Zehner } \\
\text { - unterste Zeile sind Einer }\end{array}$}
\end{tabular}

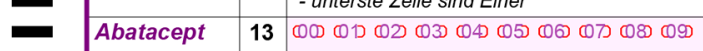

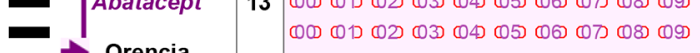

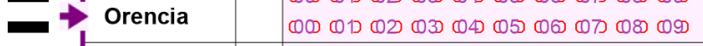

- Adalimumab 12 12 10000020300405060700809

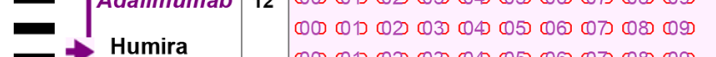

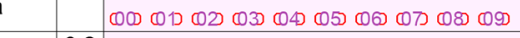

- Anakinra $\quad 0.200010020300405000700809$

$\rightarrow$ Kineret $\quad 0001002030405000700809$

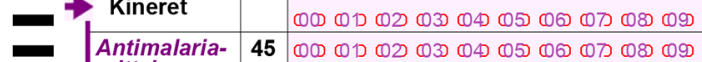

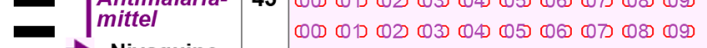

$\Rightarrow$ Nivaquine $\quad$ ए0 10020300405000700809

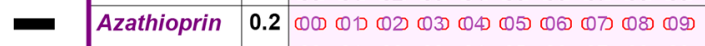

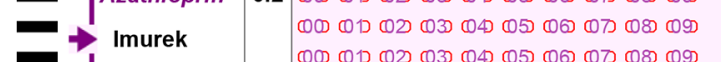

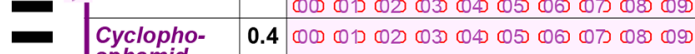

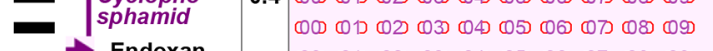

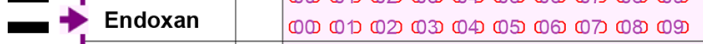

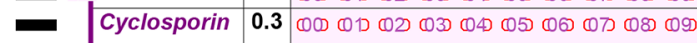

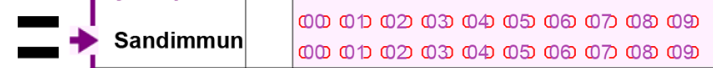

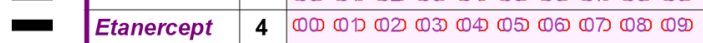

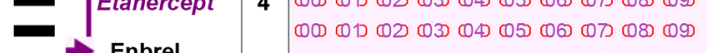

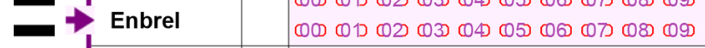

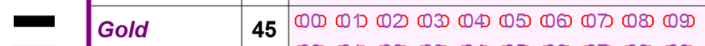

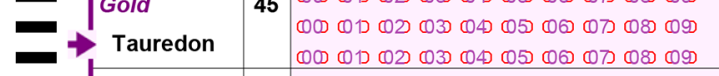

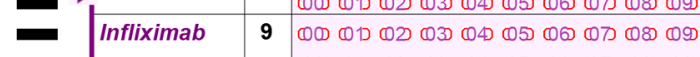

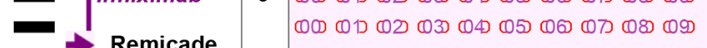

- 1 100010020300405000700809

Leflunomid $14 / 200010020300405000750809$

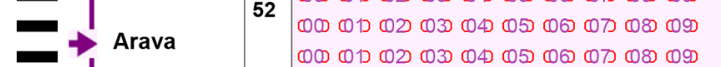

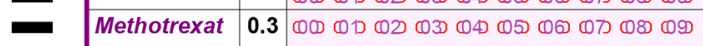

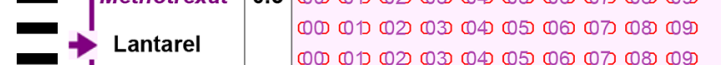

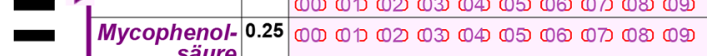

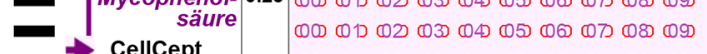

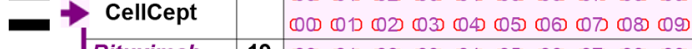

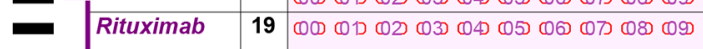

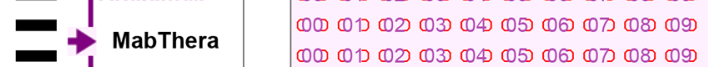

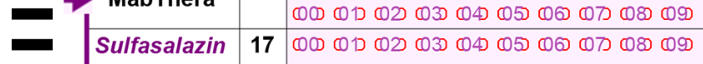

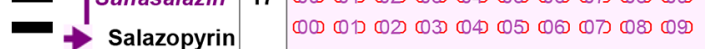

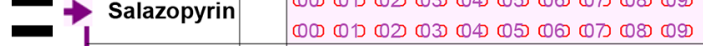

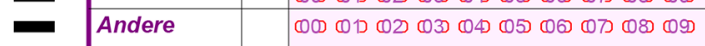

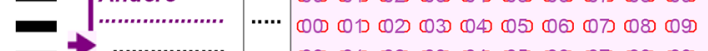

$=$ (Bitte spezifizieren)

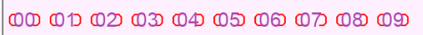

abgesetzt / ausgeschwemmt prä-op Tage $\quad$ angesetzt für Tage post-op. 0 - 99 Tage

$\begin{array}{ll}\text { max. } 2 \text { Markierungen anbringen: } & \text { Beispiel } 19 \text { Tage } \\ \text { - obere Zeile sind Zehner } & \text { Markieren }\end{array}$

$\begin{array}{lll}\text { max. } 2 \text { Markierungen anbringen: } & \text { Beispiel } & 19 \text { Tage } \\ \text { - obere Zeile sind Zehner } & \text { Markieren Sie } 01 \text { in oberer Zeile } \\ \text { - untere Zeile sind Einer } & \text { Markieren Sie } 09 \text { in unterer Zeile }\end{array}$

Markieren Sie 09 in unterer Zeile

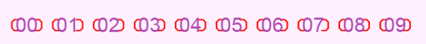

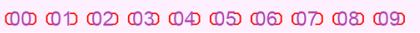

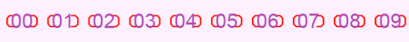

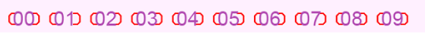

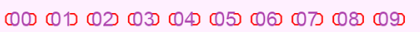

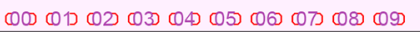

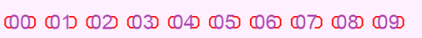

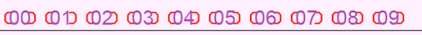

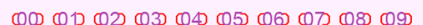

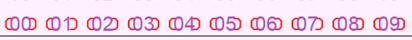

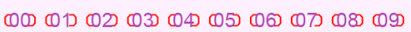

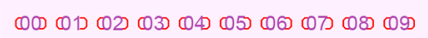

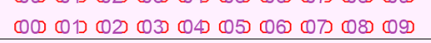

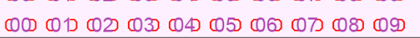

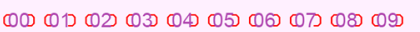

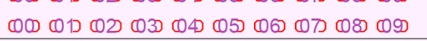

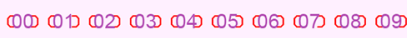

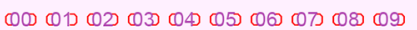

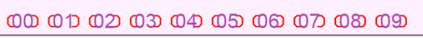

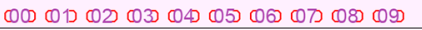

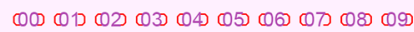

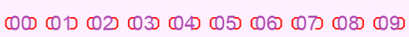

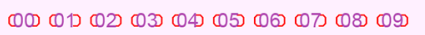

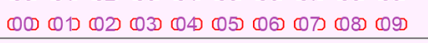

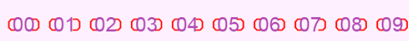

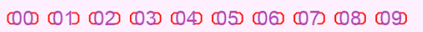

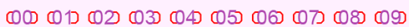

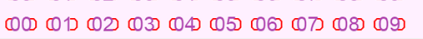

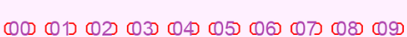

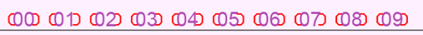

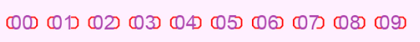

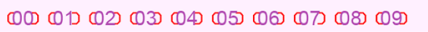

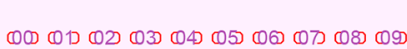

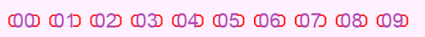

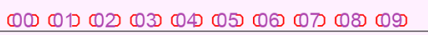

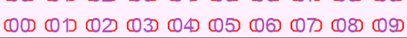

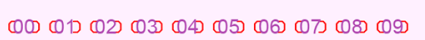

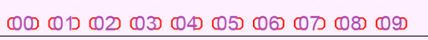

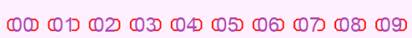

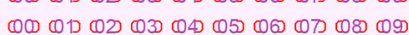

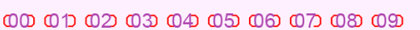

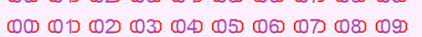

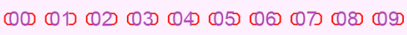

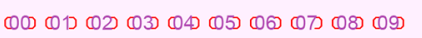

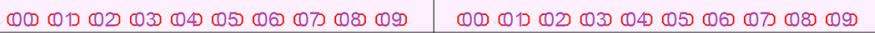

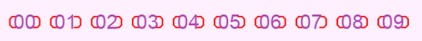

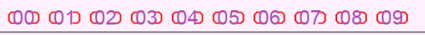

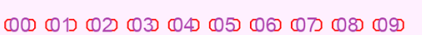

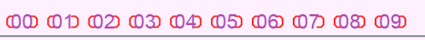

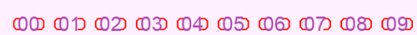

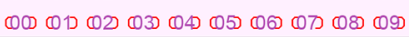

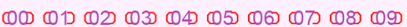

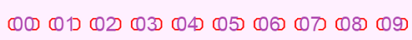

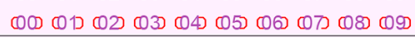

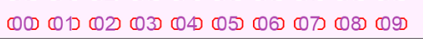

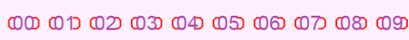

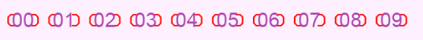

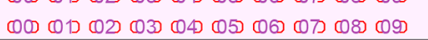

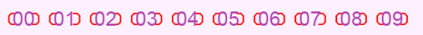

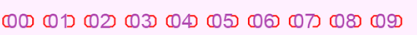
OO OD OD O3 0405000720809 
DGORh - Sammelstatistik Bogen 2

Erfassung von Komplikationen unter Basistherapie bei Rheumaoperationen

KOMPLIKATION unter

BASISTHERAPIE

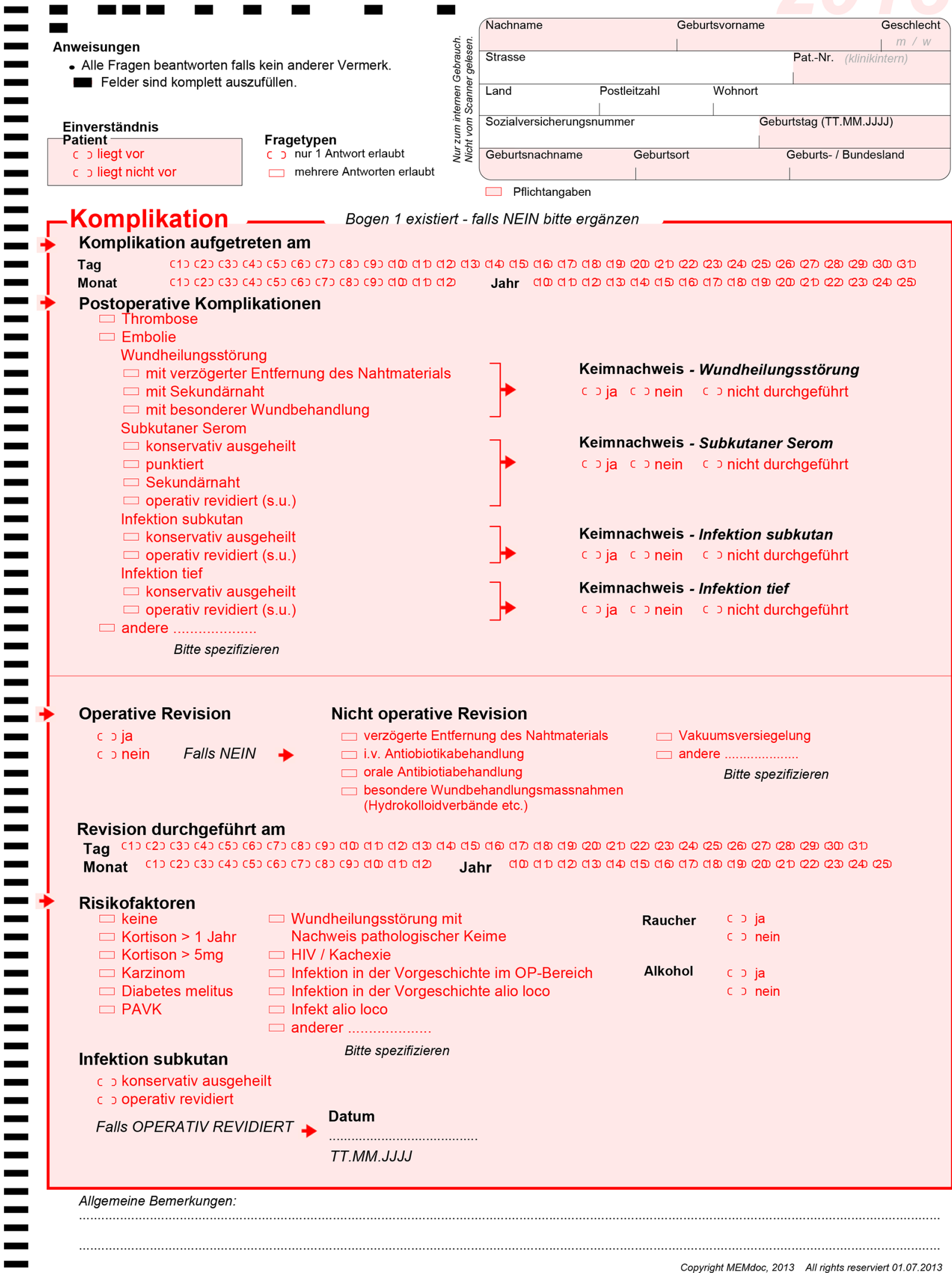

Figure 3 Questionnaires adapted for use in the registry based on the findings from the pilot study. 
Finally, based on this pilot study, additional data will be collected documenting in more detail the type of treatment wound disorders received and the final status of the wound complication, thus being able to distinguish between minor and major wound complications in the registry.

\section{LIMITATIONS}

Due to the small number of patients with observed complications as well as the inhomogeneity in the surgical and pharmacological treatments they received, extended analytical statistics could not be performed. Accordingly, at this time, no recommendations for perioperative management of anti-inflammatory drugs could be derived from these first 1000 datasets.

In the actual registry, the analysis of data reported in high volumes, like monotherapy and single surgeries, will be considered first line, while those occurring in low volumes like multiple surgeries or combinations of medication will be designated second line and will be analysed taking the first line into consideration.

\section{CONCLUSION}

Besides age, sex, risk factors, type and duration of the rheumatic disease, the administration of immune-modulating medications may impact wound complications. Due to the inhomogeneity in the disease itself and the treatments received by patients with rheumatic diseases, it is difficult to develop standardised best-practice recommendations to optimise their care. Therefore, the creation of a large, comprehensive national registry that includes the most important and relevant variables that impact the care and outcomes of these patients is essential. This pilot study has helped to identify these variables and in doing so will contribute to improving the national registry so that its data can be used to formulate accurate and relevant recommendations for the care of this vulnerable patient population.

\section{Author affiliations \\ ${ }^{1}$ Department of Orthopedics and Traumatology, Catholic Hospital Bochum, St. Josefs Hospital, University Hospital of Ruhr University Bochum, Bochum, Germany ${ }^{2}$ Institute for Medical Biometry and Epidemiology, University of Witten/Herdecke, Witten, Germany \\ ${ }^{3}$ Clinic for Orthopedics and Traumatology, Agaplesion Markus Hospital, Teaching Hospital of Johann Wolfgang Goethe University, Frankfurt am Main, Germany ${ }^{4}$ Department of Orthopedics, Rheumatic Orthopedics and Traumatology Clinic, Catholic Hospital, Dortmund, Germany \\ ${ }^{5}$ Orthopedic and Rheumaorthopedic Clinic-Diakonie Hospital, Bad-Kreuznach, Germany \\ ${ }^{6}$ Department of Rheumatic Orthopedics, Catholic Hospital Bochum, St. Elisabeth Hospital, University Hospital of Ruhr University Bochum, Bochum, Germany}

Acknowledgements Special thanks to the native speakers Professor John Barker and Kirsten Hartmann for their assistance editing the English content in this manuscript. Results from 873 pilot study patients were presented as a poster at the GMDS (German Society for Medical Computer Science, Biometry and Epidemiology)-Congress 2014 in Göttingen/Germany.
Collaborators Dr. Med. Ingo Arnold, Red Cross Hospital, Bremen, Department of Rheumatology and Orthopedics. Dr. Med. Ludwig Bause, St. JosefStift Sendenhorst, Department of Orthopedic Rheumatology. Dr. Med Harald Dinges, Westpfalzklinikum Kusel, Clinic of Orthopedics, Traumatology and Rheumatic Orthopedics. PD Dr. med. Thomas Pauly, Rheinisches Rheumazentrum St. Elisabeth Hospital, Department of Orthopedic Surgery/Rheumatology, Meerbusch Lank. Dr. Med. Stefan Schill, Joint Center, Rosenheim GmbH and Harthausen Bad Aibling Clinic. Dr. Med. Roger Scholz, Department of Orthopedics, Collm Clinic Oschatz.

Contributors TK: writing of manuscript, data analysis, modification of questionnaires for real-time registry. SR: design of pilot questionnaires, review of questionnaires for real time registry, review of manuscript. RMH: data collection and data analysis. CB: providing of references, review of manuscript. REW: providing of references, approval ethics committee. KS: design of pilot questionnaires, data collection, review of manuscript.

Funding External funding to perform this pilot study was not made available; however, permission to establish the online registry was granted by the German Orthopaedic Society (DGOOC).

Competing interests TK: Pharmaceutical or medical device companies may be involved in some of the included studies; however, the details are unknown to the author. SR: Has received speaker fees from the companies Abbvie/Grünenthal/MSD/ implantcast/medac. CB: Has received speaker fees from the companies Link and Abbot. The remaining authors declare no conflicts of interest.

Patient consent Detail has been removed from this case description/these case descriptions to ensure anonymity. The editors and reviewers have seen the detailed information available and are satisfied that the information backs up the case the authors are making.

Provenance and peer review Not commissioned; externally peer reviewed.

Data sharing statement No additional data are available.

Open Access This is an Open Access article distributed in accordance with the Creative Commons Attribution Non Commercial (CC BY-NC 4.0) license, which permits others to distribute, remix, adapt, build upon this work non-commercially, and license their derivative works on different terms, provided the original work is properly cited and the use is non-commercial. See: http://creativecommons.org/ licenses/by-nc/4.0/

(c) Article author(s) (or their employer(s) unless otherwise stated in the text of the article) 2017. All rights reserved. No commercial use is permitted unless otherwise expressly granted.

\section{REFERENCES}

1. Weiss RJ, Stark A, Wick MC, et al. Orthopaedic surgery of the lower limbs in 49,802 rheumatoid arthritis patients: results from the Swedish National Inpatient Registry during 1987 to 2001. Ann Rheum Dis 2006;65:335-41.

2. Weiss RJ, Ehlin A, Montgomery SM, et al. Decrease of RA-related orthopaedic surgery of the upper limbs between 1998 and 2004: data from 54,579 swedish RA inpatients. Rheumatology 2008;47:491-4.

3. da Silva E, Doran MF, Crowson CS, et al. Declining use of orthopedic surgery in patients with rheumatoid arthritis? results of a long-term, population-based assessment. Arthritis Rheum 2003;49:216-20.

4. Shourt CA, Crowson CS, Gabriel SE, et al. Orthopedic surgery among patients with rheumatoid arthritis 1980-2007: a populationbased study focused on surgery rates, sex, and mortality. $J$ Rheumatol 2012;39:481-5.

5. Louie GH, Ward MM. Changes in the rates of joint surgery among patients with rheumatoid arthritis in California, 1983-2007. Ann Rheum Dis 2010;69:868-71.

6. Momohara S, Inoue E, Ikari K, et al. Decrease in orthopaedic operations, including total joint replacements, in patients with rheumatoid arthritis between 2001 and 2007: data from japanese outpatients in a single institute-based large observational cohort (IORRA). Ann Rheum Dis 2010;69:312-3.

7. Krüger K, Albrecht K, Rehart S, et al. [Recommendations of the German Society for Rheumatology on the perioperative approach under therapy with DMARDs and biologicals in inflammatory rheumatic diseases]. Z Rheumatol 2014;73:77-84.

8. Louie GH, Ward MM. Changes in the rates of joint surgery among patients with rheumatoid arthritis in California, 1983-2007. Ann Rheum Dis 2010;69:868-71.

9. Gaubitz M. [Biologicals 2012]. Orthopade 2012;41:526-32. 
10. Welcker M, Sternad P, Krüger K. Aktuelle Empfehlungen der Deutschen Gesellschaft für Rheumatologie - Peroperatives Management klassischer und neuer. Antirheumatika, Orthopädie \& Rheuma 2014;17:24-9.

11. Visser K, Katchamart W, Loza E, et al. Multinational evidencebased recommendations for the use of methotrexate in rheumatic disorders with a focus on rheumatoid arthritis: integrating systematic literature research and expert opinion of a broad international panel of rheumatologists in the $3 \mathrm{E}$ Initiative. Ann Rheum Dis 2009;68:1086-93.

12. Heldmann F, Dybowski F, Baraliakos X, et al. Perioperativer Umgang mit Biologika bei rheumatoider Arthritis. Z Rheumatol 2011;70:14-20.

13. Goh L, Jewell T, Laversuch C, et al. Should anti-TNF therapy be discontinued in rheumatoid arthritis patients undergoing elective orthopaedic surgery? A systematic review of the evidence. Rheumatol Int 2012;32:5-13.

14. Pieringer $\mathrm{H}$, Danninger $\mathrm{K}$, Tzaribachev $\mathrm{N}$, et al. Patients with arthritis undergoing surgery: how should we manage tumour necrosis factor blocking agents perioperatively? A systematic literature review. Yonsei Med J 2013:54:253-7.

15. Krüger K. Perioperative medikamentöse therapie rheumatischer erkrankungen-Aktuelle Empfehlung der DGRh. Arthritis Rheum 2014;60:158-62.
16. Ravi B, Escott B, Shah PS, et al. A systematic review and metaanalysis comparing complications following total joint arthroplasty for rheumatoid arthritis versus for osteoarthritis. Arthritis Rheum 2012;64:3839-49.

17. den Broeder AA, Creemers MC, Fransen J, et al. Risk factors for surgical site infections and other complications in elective surgery in patients with rheumatoid arthritis with special attention for antitumor necrosis factor: a large retrospective study. $J$ Rheumatol 2007;34:689-95.

18. Strangfeld A, Eveslage M, Schneider M, et al. Treatment benefit or survival of the fittest: what drives the time-dependent decrease in serious infection rates under TNF inhibition and what does this imply for the individual patient? Ann Rheum Dis 2011;70:1914-20.

19. Combe B, Landewe R, Lukas $\mathrm{C}$, et al. EULAR recommendations for the management of early arthritis: report of a task force of the European Standing Committee for International Clinical Studies Including Therapeutics (ESCISIT). Ann Rheum Dis 2007;66:34-45.

20. Doran MF, Crowson CS, Pond GR, et al. Frequency of infection in patients with rheumatoid arthritis compared with controls: a population-based study. Arthritis Rheum 2002;46:2287-93.

21. Rehart S, Petak N. Modern disease modifying drugs in rheumatoid arthritis in the perioperative period. patients with rheumatic diseases under therapy with methotrexate, leflunomide or TNF-alpha blockers in the perioperative period. Akt Rheumatol 2007;32:74-7. 